\title{
Ragweed pollen and allergic symptoms in children: results from a three-year longitudinal study
}

Authors: Natalia R Jones ${ }^{a^{*}}$, Maureen Agnewa, Ivana Banic ${ }^{\mathrm{b}}$, Carlota M Grossi ${ }^{\mathrm{a}}$, Felipe J ColónGonzález ${ }^{a}$, Davor Plavec ${ }^{b, c}$, Clare M. Goodess ${ }^{a}$, Michelle M. Epstein ${ }^{e}$, Mirjana Turkalj ${ }^{b, c, d}$ and lain R Lake $^{\mathrm{a}}$.

aSchool of Environmental Sciences, University of East Anglia UEA, Norwich NR4 7TJ, UK;

n.jones@uea.ac.uk; m.agnew@uea.ac.uk; c.grossi-sampedro@uea.ac.uk; f.colon@uea.ac.uk;

c.goodess@uea.ac.uk; i.lake@uea.ac.uk

'Srebrnjak Children's Hospital, Srebrnjak 100, 10000 Zagreb, Croatia;

'Faculty of Medicine, J.J.Strossmayer University of Osijek, J. Huttlera 4, 31000 Osijek, Croatia

${ }^{d}$ Catholic University of Croatia, llica 242, 10000 Zagreb, Croatia

cosic@bolnica-srebrnjak.hr; plavec@bolnica-srebrnjak.hr; turkalj@bolnica-srebrnjak.hr

'Medical University of Vienna, Department of Dermatology; Währinger Gürtel 18-20, 1090 Vienna, Austria;

michelle.epstein@meduniwien.ac.at

*Corresponding author: n.jones@uea.ac.uk 


\section{Graphical abstract}

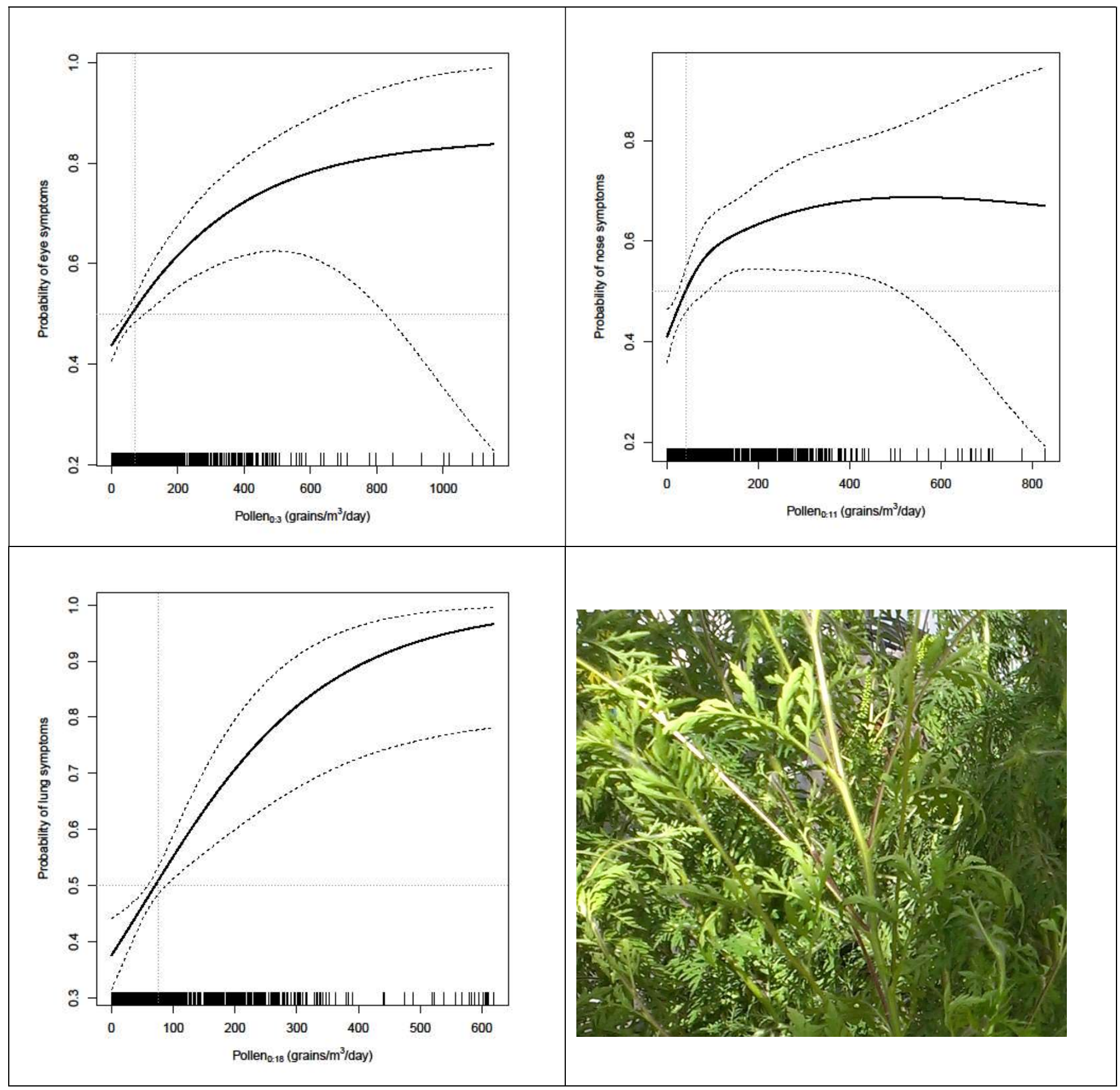




\begin{abstract}
Common Ragweed is a highly allergenic invasive species in Europe, expected to become widespread under climate change. Allergy to ragweed manifests as eye, nasal and lung symptoms, and children may retain these throughout life. The dose-response relationship between symptoms and pollen concentrations is unclear. We undertook a longitudinal study, assessing the association between ragweed pollen concentration and allergic eye, nasal and lung symptoms in children living under a range of ragweed pollen concentrations in Croatia. Over three years, 85 children completed daily diaries, detailing allergic symptoms alongside daily location, activities and medication, resulting in 10,130 individual daily entries. The daily ragweed pollen concentration for the children's locations was obtained, alongside daily weather and air pollution. Parents completed a home/lifestyle/medical questionnaire. Generalised Additive Mixed Models established the relationship between pollen concentrations and symptoms, alongside other covariates. Eye symptoms were associated with mean daily pollen concentration over four days (day of symptoms plus 3 previous days); 61 grains $/ \mathrm{m}^{3} /$ day $(95 \% \mathrm{Cl}: 45,100)$ was the threshold at which $50 \%$ of children reported symptoms. Nasal symptoms were associated with mean daily pollen concentration over 12 days (day of symptoms plus 11 previous days); the threshold for $50 \%$ of children reporting symptoms was 40 grains $/ \mathrm{m}^{3} /$ day $(95 \% \mathrm{Cl}: 24,87)$. Lung symptoms showed a relationship with mean daily pollen concentration over 19 days (day of symptoms plus 18 previous days), with a threshold of 71 grains $/ \mathrm{m}^{3} /$ day $(95 \% \mathrm{Cl}: 59,88)$. Taking medication on the day of symptoms showed higher odds, suggesting responsive behaviour. Taking medication on the day prior to symptoms showed lower odds of reporting, indicating preventative behaviour. Different symptoms in children demonstrate varying dose-response relationships with ragweed pollen concentrations. Each symptom type responded to pollen exposure over different time periods. Using medication prior to symptoms can reduce symptom presence. These findings can be used to better manage paediatric ragweed allergy symptoms.
\end{abstract}

\title{
Highlights
}

- The dose-response between ragweed concentrations and allergy symptoms is unclear

- We used a longitudinal study to determine daily allergy symptoms in 85 children

- Associations between daily symptoms and ragweed concentrations were examined

- Generalised Additive Mixed Models (GAMM) were used for analysis

- Symptom types showed different non-linear associations with ragweed concentration

- Symptom types responded to pollen exposure over differing time periods

\section{Keywords}

Ambrosia artemisiifolia; Allergic rhinitis; asthma; daily diary; daily pollen count; Croatia 


\section{Introduction}

Ambrosia artemisiifolia (hereafter ragweed) is a herbaceous plant native to North America. In Europe, ragweed is an introduced species (Smith et al., 2013) in the process of an ongoing invasion event (Storkey et al., 2014). Each ragweed plant produces over one billion pollen grains (Fumanal et al., 2007) which are highly allergenic (Smith et al., 2013). The concentration of ragweed pollen in the atmosphere varies considerably across Europe, from a total absence up to an annual count of over 25000 pollen grains $/ \mathrm{m}^{3} /$ year (Matyasovszky et al., 2018). The ragweed sensitisation rate (the proportion of people developing an allergic reaction to a substance via a skin prick test) is above $2 \%$ in all European countries (Burbach et al., 2009), with rates varying from $50-60 \%$ in Hungary (Burbach et al., 2009), to 14-20\% in Germany (Ruëff et al., 2012) and less than 3\% in France, Spain, Italy, Sweden and the UK (Bousquet et al., 2007).

Allergy to ragweed predominantly manifests clinically as allergic rhino-conjunctivitis and allergic asthma (Bass et al., 2000; Salo et al., 2014). The symptoms occur in late summer/autumn and include nasal congestion, ocular redness, itching of the nose or eyes, sneezing, runny nose, coughing, wheezing and dyspnoea. Rhino-conjunctivitis and asthma are commonly co-morbid (Leynaert et al., 2000). The burden of ragweed allergy goes beyond physical symptoms however, with impacts on sleep quality (Meltzer et al., 2009; Nathan, 2007), school attendance (Nathan, 2007; Kay, 2000; Sennhauser et al., 2005), lost workdays (Nathan, 2007) and emotional and social health (Nathan, 2007; Meltzer et al., 2009; Sennhauser et al., 2005), all of which have negative effects on overall quality of life and economic well-being (Meltzer et al., 2009; Sennhauser et al., 2005; Nathan, 2007). Zuberbier et al. (2014) have calculated that the economic burden of allergic disease in the EU is between $€ 55$ and $€ 151$ billion per annum.

Climate change is likely to impact on ragweed allergy in Europe. Under climate change it is expected that the distribution of ragweed in Europe will expand to areas where it is currently not found (Storkey et al., 2014). By 2060, it is predicted that the quantity of ragweed pollen that the population will be exposed to will substantially increase, and the pollen season will lengthen (Lake et al., 2017). Alongside this, by 2060 the rate of sensitisation to ragweed is predicted to more than double across Europe, with rates increasing both in areas where ragweed is currently prevalent and where it is presently uncommon (Lake et al., 2017). Thus, as a result of the increase in pollen concentrations, ragweed pollen allergy will become an increasingly common health problem across Europe (Lake et al., 2017).

Despite this large and growing health problem, very few studies have investigated the associations between ragweed pollen levels and allergy symptoms, and the effect of pollen exposure on childhood rhino-conjunctivitis is largely unknown (Cakmak et al., 2002). In Italy, Albertini et al. (2012) described a correlation between the number of (mainly adult) patients with asthmatic symptoms and the total annual ragweed pollen concentration. In the USA, 24 asthma patients aged 9-64 completed a symptom diary over a two month period, and correlated asthma and rhinitis symptoms with environmental factors. The study found a positive correlation between symptoms and ragweed pollen levels (Newhouse and Levetin, 2004). Studies in Canada have shown an association between ragweed concentration and physician visits for rhinitis in the elderly (Villeneuve et al., 2006) and patients of all ages (Breton et al., 2006). In France, a country where the average total annual ragweed pollen count varies geographically from 4 pollen grains $/ \mathrm{m}^{3} /$ year to 5374 pollen grains $/ \mathrm{m}^{3} /$ year (Thibaudon et al., 2014), a more extensive longitudinal study using daily diaries over 
two years found a significant positive linear relationship between ragweed exposure and daily hay fever symptoms in 30 adults sensitised to ragweed (Caillaud et al., 2014). Despite both laboratory (Naclerio et al., 1983; Solomon, 1984) and clinical (Comtois and Gagnon, 1988; Peternel et al., 2008) studies, no precise ragweed pollen threshold for triggering allergy symptoms has been established (Peternel et al., 2008). To our knowledge there are no longitudinal studies examining the doseresponse relationship between ragweed pollen levels and paediatric allergic symptoms, focused on areas with a range of ragweed pollen concentrations including very high levels.

The aim of this study is to examine how daily ragweed pollen levels influence a range of allergy symptoms in a cohort of ragweed-sensitised children in Croatia. Croatia is considered one of the most ragweed affected countries in Europe (Rybníček and Jäger, 2001; Peternel et al., 2005; Galzina et al., 2010) with annual pollen counts measuring up to 24801 pollen grains $/ \mathrm{m}^{3} /$ year (Peternel et al., 2005 ) in the most highly infested areas. Given the predicted increase in pollen concentrations across Europe (Lake et al., 2017), it is important to investigate the associations between pollen concentrations and symptoms in areas which already have high pollen concentrations. Children are useful to study as their epidemiological history is less complex than adults, and children who develop symptoms early are likely to retain them later in life (Rhodes et al., 2002; Illi et al., 2006). To our knowledge, this is the first longitudinal study to examine the dose-response relationship between a range of daily allergy symptoms and ragweed pollen in European children.

\section{Methods}

The purpose of this study is to use an epidemiological study design to explore the relationship between observed levels of pollen in the environment and reported symptoms in children, controlling for a range of confounding variables.

\subsection{Study design}

Between April 2012 and June 2014, 4015 children were recruited through schools and kindergartens from three areas of Croatia representing a range of ragweed levels: Dalmatia (low pollen: average total annual pollen 422 grains $/ \mathrm{m}^{3} /$ year), Zagreb (medium pollen: average total annual pollen 5189 grains $/ \mathrm{m}^{3} /$ year) and Slavonia (high pollen: average total annual pollen 13079 grains $/ \mathrm{m}^{3} /$ year). Children with chronic immunosuppressant or antihistamine therapy were excluded from participating as these interfere with skin prick tests. Using standard allergy skin prick tests (allergen extract Alyostal ST-IR, Stallegenes S.A. France), children were tested for sensitisation to a palette of aeroallergens including ragweed. From these recruits, 85 children who were sensitised to Ambrosia (defined as a wheal size $>2 \mathrm{~mm}$ ) volunteered to complete a daily symptom diary, developed from a standardised allergy symptom and medication use questionnaire (see www.pollendiary.com; Voukantsis et al. (2015)). Altogether $55 \%$ of the children were also sensitised to cross-reactive pollens (birch, hazel, pine, olive, grass, and Parietaria pollen). The children (or their parents) recorded their daily symptoms and activity over the pollen season $\left(22^{\text {nd }}\right.$ July to $31^{\text {st }}$ October $)$ for the years 2012 ( 29 children), 2013 (49 children) and 2014 (24 children). Sixteen children completed diaries on multiple years. Further details of the recruitment and diagnostic tests are detailed elsewhere (Agnew et al., 2018).

\subsection{Daily diary, pollen, environment and lifestyle data}


The symptom diaries included details of the children's daily allergy symptoms. Eye symptoms (itching, redness, foreign body sensation and watering), nasal symptoms (itching, sneezing, running and blocked nose) and lung symptoms (wheezing, shortness of breath, cough and asthma) were recorded. An overall score for each set of symptoms was produced, indicating the "presence" of any symptom or the "absence" of any symptoms. Altogether three dichotomous symptom measures were generated: reported any eye symptoms (yes/no), reported any nasal symptoms (yes/no) and reported any lung symptoms (yes/no). The daily geographical locations of the children were detailed, indicating whether they were at home or at another location (e.g. on holiday) and where they were located on a two hourly basis each day (home, school, outside). The activities they were participating in on a two hourly basis were also recorded (including sleeping, resting/learning, sport). Any medication the child had taken was noted.

Using Geographical Information Systems (GIS) (ArcGIS 10.2), each child was assigned to their nearest pollen observation site (Croatian Environment Agency). Daily measures of ragweed pollen (grains $/ \mathrm{m}^{3}$ ) were obtained for the child's location (either home or away) giving each child an individual pollen grain measure for each diary day, based on their location. Figure 1 presents raw data showing the crude relationships between total daily pollen grains $/ \mathrm{m}^{3}$ (in percentiles) and the percentage of days when children reported symptoms. For all three symptoms the percentage of days when children reported symptoms increases with pollen grains $/ \mathrm{m}^{3}$ that day.

Children were allocated to their nearest weather and air quality stations, from where potential confounding variables including daily temperature, rainfall and air quality data (mean concentration of $\mathrm{SO}_{2}, \mathrm{PM} 10, \mathrm{NO}_{2}, \mathrm{O}_{3}$ ) for their daily location was obtained. In addition, a parental questionnaire collected information on the home environment, lifestyle, family/personal medical history and socioeconomic information (ISAAC Phase II questionnaire - see

http://isaac.auckland.ac.nz/phases/phasetwo/phasetwo.html; Asher et al. (1995)). Also using GIS, information on the home environment was determined, such as whether the home was in a rural or urban area, based on CORINE Land cover data (European Environment Agency (2015); see Agnew et al. (2018) for more details). The study protocol and informed consent, based on the international Declaration of Helsinki, Declaration on Human Rights and local legislation, were approved by the Local Ethics Committee (Children's Hospital Srebrnjak, Croatia) and the E.U. ATOPICA project Ethics Committee.

\subsection{Statistical analysis}

Generalised Additive Mixed Models, GAMM (Wood, 2006) with a binomial specification were used to evaluate the potential non-linear and delayed associations between the exposure to ragweed pollen and the presence of symptoms. GAMMs are semi-parametric extensions of generalised linear models where the linear predictor is replaced by a sum of smooth functions (Hastie and Tibshirani, 1986). One advantage of GAMMs is that they automatically estimate the optimal degree of nonlinearity of a model directly from the data (Wood, 2006). Separate models were run for reported eye, nasal and lung symptoms. All analyses were undertaken in R version 3.4.4 (R Core Team 2018).

When investigating the impact of pollen on allergic symptoms it is common to consider pollen over the consecutive days prior to symptoms, as in epidemiological studies lagged relationships are often found (Breton et al., 2006; Villeneuve et al., 2006; Erbas et al., 2018). It is also suggested that the clinical response to pollen tends to increase as the pollen season develops (Tobias et al., 2004), the 
sustained effect of environmental stimuli potentially have cumulative long-lasting effects (Frey and Suki, 2008) and that elevated concentrations of pollen from previous days can have an additive effect, resulting in heightened allergy symptoms (Newhouse and Levetin, 2004). Therefore, to account for lagged and cumulative effects of pollen on symptoms, the influence of pollen on the days previous to the symptom day were examined. Individual associations between symptoms on a day and the pollen concentration on the days previous to the symptoms were examined (see Supplementary Table S1). The continuous days where the individual association between daily pollen concentration and symptoms was $p<0.01$ were used to compute a mean daily pollen concentration measure. The number of days where pollen had an influence varied for the different symptoms. Four days (day of symptoms plus the three previous days) for eye symptoms (Pollen03), 12 days (day of symptoms plus the 11 previous days) for nasal symptoms (Pollen011) and 19 days (day of symptoms plus the 18 previous days) for lung symptoms (Pollen018). The mean pollen concentrations over these time periods were included in the model as the main pollen measure. Zheng et al. (2015) suggest that lags are essential in time-series studies to better determine the effects of outdoor air pollution on asthma outcomes and thus we used matching time lags to account for any potential effect of $\mathrm{SO}_{2}, \mathrm{PM10}, \mathrm{NO}_{2}$, and $\mathrm{O}_{3}$ on the presence of symptoms.

In the development of the models, all variables shown in Agnew et al. (2018) to be associated with ragweed sensitised children and the development of allergic disease were included as potential explanatory variables, alongside additional time series measures (day, year and measure of early or late season, child locations, daily symptoms, daily medication, daily activity, weather, air pollutants). A core model was developed including the unique identifier of each child, the unique identifier for each area, mean daily pollen concentration, mean daily temperature $\left({ }^{\circ} \mathrm{C}\right)$, total daily rainfall $(\mathrm{mm} /$ day), gender, age group and year. Also included was the logarithm of the binary symptom scores lagged one day to account for potential temporal correlation in the data (Imai et al., 2015). Any other variables adding to the explanatory power of the model were retained. A full list of potential explanatory variables is shown in Supplementary Table S2. The general algebraic definition of the core model is given by:

$$
\ln \left[\frac{p}{1-p}\right]=\alpha+I D+\text { Area }+\ln \left(S_{t-1}\right)+\text { Year }+ \text { Age }+ \text { Sex }+\sum_{p=1}^{P} \beta(X)+s\left(Z_{0: L}\right)
$$

where $p$ denotes the probability of the symptoms occurring and $0<p<1 ; \alpha$ is the intercept; ID indicates the child specific random effects; Area is the area-specific random effects; $\ln \left(S_{t-1}\right)$ is the natural logarithm of the symptoms on the previous day; Year is a categorical variable for each year in the records; Age corresponds to the age group of the child; Sex indicates the gender of the child; $B$ is the coefficient of each weather variable $(X)$ in the model; and $s$ denotes the smooth function of pollen (Z) lagged zero to $L$ days.

For each predictor not present in the core model, we iteratively incorporated the predictor leading to the lowest Akaike's information criterion (AIC) until no further variable incorporations lowered the AIC. Supplementary Table S3 shows the change in AIC for each additional variable. Model selection was conducted using the AIC because it performs better than hypothesis-based approaches (Mazerolle, 2006). Notably, the AIC as a value is meaningless by itself and is meaningful only when compared with other AIC values from other models. The model with the lowest AIC is considered the most adequate model (Symonds and Moussalli, 2011). Within the models, some non-significant 
variables have been retained when they improve the fit of the model. There were no patterns in the residual plots, confirming these as the most appropriate models.

\section{Results}

Altogether, 85 children completed diaries over 306 days that covered three ragweed pollen seasons, resulting in 10,130 individual daily diary entries. In total, $38 \%$ of the children were girls, their ages ranged from 4 to 12 and 63\% lived in the Zagreb area, whilst 29\% lived in Slavonia and $7 \%$ in Dalmatia. Of the 85 children, 56 (66\%) reported eye symptoms, 75 (88\%) reported nasal symptoms and $41(48 \%)$ reported lung symptoms. Table 1 summarises the main characteristics of the children in the study.

In the eye model, mean daily pollen concentrations were based on four days (day of symptoms plus previous three days - Pollen03). The dose-response relationship between the mean daily pollen concentration (Pollen03) and the probability of reported eye symptoms is shown in Figure 2 . The $X$ axis represents increasing levels of pollen (expressed in grains $/ \mathrm{m}^{3} /$ day). The rug (lines) at the bottom indicates the density of observations at each level of pollen. The majority of children were exposed to a mean daily pollen concentration (Pollen03) of less than 500 grains $/ \mathrm{m}^{3}$. The $Y$ axis shows the probability of reported eye symptoms. The smooth line indicates the maximum likelihood estimates for the risk of symptoms, and the dashed lines represent the $95 \%$ confidence intervals. The relationship between pollen and the risk of symptoms was non-linear. There was an increase in the probability of symptoms up to around 500 grains $/ \mathrm{m}^{3} /$ day after which the relationship flattens; however, the large confidence intervals at pollen levels above 500 grains $/ \mathrm{m}^{3} /$ day suggest large uncertainties in the association between reported eye symptoms and pollen at high pollen levels. These large confidence intervals were the result of low numbers of children being exposed to these levels of pollen. The dotted lines indicate the threshold of pollen where $50 \%$ of children reported symptoms. For eye symptoms it was 61 grains $/ \mathrm{m}^{3} /$ day (95\% confidence intervals: 45,100 ).

Table 2 contains the model for the reported presence or absence of eye symptoms. Predictors which showed significantly lower odds of reported eye symptoms included being ten years or older, being away from home, taking nasal sprays or drops on the day before reported symptoms and increased time spent being active outside. Conversely, reporting symptoms on the day previous, taking nasal sprays or drops on the day, the year 2013 and daily temperature showed significantly higher odds of reported eye symptoms.

In the nasal model, mean daily pollen concentrations were based on 12 days of pollen (day of symptoms plus previous 11 days - Pollen011). Figure 3 shows the dose-response relationship between mean daily pollen concentration (Pollen011) and the probability of reported presence of nasal symptoms. As can be seen from the rug, most children were exposed to a mean daily pollen concentration (Pollen011) of less than 400 grains $/ \mathrm{m}^{3}$. There was a non-linear and positive relationship between the mean daily pollen concentration and the risk of reported nasal symptoms. The increase in the risk of reported nasal symptoms was steeper at levels between 0 and 100 grains $/ \mathrm{m}^{3} /$ day after which the relationship gradually started to flatten. For nasal symptoms the threshold for reported symptoms to appear in $50 \%$ of children was 40 grains $/ \mathrm{m}^{3} /$ day $(95 \%$ confidence intervals: 24,87$)$. 
The model for the associations with the reported presence or absence of nasal symptoms is shown in Table 3. Being away from home and the rainfall on the day of measurement showed lower odds. Reporting nasal symptoms on the previous day, taking nasal sprays or drops on the day, and mean daily temperature increased the odds of reported nasal symptoms.

In the lung model, mean daily pollen concentration was based on 19 days of pollen (day of symptoms plus previous 18 days - Pollen018). Figure 4 highlights the dose-response relationship between the probability of reported lung symptoms and the mean daily pollen concentration (Pollen018). Most children were exposed to a mean daily pollen concentration below 350 grains $/ \mathrm{m}^{3} /$ day. There was a non-linear and positive relationship between pollen concentration and the risk of reported lung symptoms, with the relationship starting to flatten around 300 grains $/ \mathrm{m}^{3} /$ day. Approximately 71 grains $/ \mathrm{m}^{3} /$ day $(95 \%$ confidence intervals: 59,88$)$ was the threshold which triggered the reported appearance of lung symptoms in $50 \%$ of children.

Table 4 shows the model for reported lung symptoms. Time spent being active and the year 2014 showed significantly lower odds. Higher odds of reported lung symptoms were significantly associated with reported lung symptoms on the previous day and taking asthma medication on the same day.

\section{Discussion}

When examining the relationship between ragweed pollen concentration and reported symptoms, lagged and cumulative effects were considered, as in previous studies (Breton et al., 2006; Villeneuve et al., 2006; Erbas et al., 2018). The number of days when ragweed pollen was associated with symptoms varied for the different symptomologies. For eye symptoms, only pollen levels on the day of symptoms plus the three previous days were relevant, suggesting that eye symptoms are an immediate response to ragweed pollen. Nasal symptoms were an longer response, as the ragweed pollen concentration over the day of symptoms plus the 11 previous days were associated with nasal symptoms. Meanwhile, the response of the lungs to ragweed pollen exposure was over the longest period, as the day of symptoms plus the 18 previous days were associated with lung symptoms. To our knowledge, no other studies have investigated the pollen lag structure for selfreported symptoms in children. Where the impact of ragweed pollen on symptoms has been examined, there is little consistency in the length of lags, with studies showing five (Breton et al., 2006), ten (Villeneuve et al., 2006) and 15 (Newhouse and Levetin, 2004) days of pollen impacting on allergic rhinitis (Breton et al., 2006; Villeneuve et al., 2006), and asthma and allergic rhinitis (Newhouse and Levetin, 2004).

There is a non-linear positive dose-response relationship between ragweed pollen concentration and reported eye, nasal and lung symptoms, although this relationship differs for the three types of reported symptoms. Interestingly, Caillaud et al. (2014), who investigated both linear and non-linear relationships between hay fever symptoms in adults and ragweed pollen counts, observed a linear relationship, at a lower range of pollen levels (ranging from $0-543$ grains $/ \mathrm{m}^{3} /$ day).

For all reported symptoms, taking medication on the day of symptoms was associated with a significantly greater chance of symptoms occurring, as was found in the French study (Caillaud et al., 2014). It is unclear whether reported medication was taken for prevention or relief of symptoms, 
however our findings suggest that taking medication on the day is a response to symptoms, rather than preventative. Our study also showed that taking medication on the previous day was significantly associated with a lower likelihood of reported eye symptoms. In particular, taking nasal sprays or nose drops on the previous day was associated with a lower likelihood of reported eye symptoms. The links between nasal and ocular symptoms remain unclear (Siroux et al., 2018), however, pathways of nasal-ocular communication are thought to increase the risk of inflammation at both sites following allergen exposure (Bielory, 2010) and nasal sprays are used as treatments for ocular symptoms associated with allergic rhinitis (Naclerio, 2008). Thus, the association between the use of nasal sprays and eye symptoms is plausible. Very few children in the study reported the use of eye drops and therefore these were not included in the models. The use of anti-allergy tablets was retained in the lung model because it added explanatory power, although it was not significant. Our findings indicate taking medication on the day before symptoms has a positive effect on reducing eye symptoms, thus it is interesting that, despite the recognised links between nasal medication and ocular symptoms (Naclerio, 2008), many children are not using these medications and are symptomatic for many days. In this cohort, 15 children reported eye symptoms on at least one day and took no nasal sprays or nose drops, while 11 children reported eye symptoms for more than seven days and took no nasal sprays or nose drops. As Croatia has a ragweed pollen forecast system in place (Peternel et al., 2005; Andrija Stampar Teaching Institute of Public Health, 2019) information is available to allow for the commencement of regular treatment in advance of the ragweed pollen season (Scadding, 2015) as a pragmatic approach to current and likely future increasing pollen levels and hence symptoms.

There has long been a question over the impact of physical activity on allergy symptoms (Lucas and Platts-Mills, 2005). Our study shows that being active outdoors is associated with a lower likelihood of reported eye symptoms, while being active either indoors or outdoors was associated with a lower probability of lung symptoms. A Greek investigation has shown a trend towards a reduction in asthma symptoms amongst children who participate in physical activity outdoors (Kosti et al., 2012). However, it has been suggested that children with allergy symptoms are less likely to participate in exercise, sport or playing with friends (Meltzer et al., 2009) and thus those being active may be those who suffer fewer symptoms. Further investigation into the relationship between allergy symptoms and both indoor and outdoor physical activity is required.

Weather also influenced allergic symptoms, independently of the impact of weather on pollen. Higher daily temperature was associated with an increased likelihood of reported eye and nasal symptoms, which supports previous data (Medek et al., 2012). Conversely, rainfall has a protective impact on reported nasal symptoms, which is similar to an Australian study which found that allergy symptoms decreased after rainfall events (Medek et al., 2012) but differs from a European study which found asthma and wheeze to be positively associated with rainfall (Arnedo-Pena et al., 2013). Further investigation is required to determine how temperature and rainfall drive allergic symptoms independently of pollen.

The majority of our study participants who stated they were away from home had travelled from a higher pollen area to a lower pollen area. Being away from home was protective for eye and nasal symptoms, but not for lung symptoms. This effect is seen even controlling for changing pollen levels. This suggests that there is a protective effect on eye and nasal symptoms of moving from an 
area with a high ragweed pollen load to an area with a lower load, which is not captured by our mean daily pollen concentrations (Pollen03, Pollen011). The reasons for this are unclear.

We considered whether the day of the week was important, as nasal symptoms have been shown to vary between week days and weekends in adults (Caillaud et al., 2014), but this measure was not significant and did not improve the fit of the model. This may be because we were looking at children rather than adults and because much of the ragweed season occurs during the school holidays, when inter-day activities may be similar.

Our study demonstrates that it is possible to collect extensive self-reported diary data on the allergy symptoms and behaviour of children aged 4-12 over a three-year period. Previous studies indicate that the use of personal diaries to collect data on allergy symptoms is valid in adults (Jantunen et al., 2012; Globe et al., 2015) and children (Casas et al., 2017). However, there are limitations to our study. As the symptoms measured were self-reported and not medically determined, it is not possible to assess their clinical importance. However, any self-reported symptoms affecting daily activities might be considered important, and Bousquet et al. (2018) have shown that using a simple electronic self-report method can accurately assess nasal symptoms. The children (or their parents) were self-selecting for the overall study and although those invited to participate in the diary element were chosen because of their ragweed sensitisation, they participated voluntarily. This may result in a biased sample, but the analysis focus was differences in symptoms over time and not between children. There was an uneven sampling distribution of participant age (62\% aged 7-9), gender (62\% male) and geographic location (64\% in the Zagreb area). Participant numbers also varied across ragweed seasons, with almost twice as many in 2013 (49) than in 2012 (29) and 2014 (24). However, all these factors were controlled for in the analysis.

Measurements from pollen observation stations may not reflect the levels of pollen to which children are exposed. In this study, children were selected if their school was within $15 \mathrm{~km}$ of a ragweed pollen station (Agnew et al., 2018). However, pollen levels will vary within this zone, and additionally, the location of the child's home and daily activities may be outside this zone. Wherever possible if the child was away from home (e.g. on holiday), values from the nearest pollen station to their known location were used, but this may have been greater than $15 \mathrm{~km}$. Therefore, the actual pollen level the child was exposed to may differ from the measured amount. The same limitations hold for the weather and air quality data, where observation networks are sparser.

To our knowledge, this is the first study to examine reported daily allergy symptoms and ragweed pollen in European children living under a range of pollen concentrations, including areas with very high ragweed pollen concentrations. We have examined the influence of daily ragweed pollen on the reported presence or absence of allergy symptoms in Croatian children keeping a daily symptom diary and used these to develop dose-response curves. We have demonstrated lag effects on symptoms, the pollen thresholds needed for symptoms to occur and highlighted how different symptoms respond to different pollen exposure levels. Under future conditions of climate change, it is predicted that the distribution of ragweed will expand throughout Europe (Storkey et al., 2014) and the numbers of people sensitised to this allergen could more than double (Lake et al., 2017). Thus, the numbers of people suffering allergy symptoms due to ragweed exposure is likely to increase. The findings from this study could be used to address this challenge by combining the dose-response curves developed with predictive pollen modelling (such as in Voukantsis et al. 
(2010)) to develop early warning systems and provide allergy sufferers with adequate information to allow them to better pre-empt and manage allergy symptoms.

Funding: This study was carried out within the 'Atopic diseases in changing climate, land use and air quality' (ATOPICA) FP7 Project, under grant agreement \#282687. IL and FCG are partly funded by the National Institute for Health Research, Health Protection Research Unit in Emergency Preparedness and Response at King's College London.

\section{Tables}

Table 1: Summary characteristics of children

\begin{tabular}{|c|c|c|}
\hline & & $\begin{array}{l}\text { Number of children (\%) } \\
\qquad(n=85)\end{array}$ \\
\hline \multirow{7}{*}{$\begin{array}{l}\text { Age at entry } \\
\text { into study }\end{array}$} & 4 & $9(11 \%)$ \\
\hline & 5 & $6(7 \%)$ \\
\hline & 6 & $7(8 \%)$ \\
\hline & 7 & $16(19 \%)$ \\
\hline & 8 & $16(19 \%)$ \\
\hline & 9 & $21(25 \%)$ \\
\hline & 10 & $10(12 \%)$ \\
\hline \multirow{2}{*}{ Gender } & Male & $53(62 \%)$ \\
\hline & Female & $32(38 \%)$ \\
\hline \multirow{3}{*}{ Pollen season ${ }^{a}$} & 2012 & $29(34 \%)$ \\
\hline & 2013 & $49(57 \%)$ \\
\hline & 2014 & $24(28 \%)$ \\
\hline \multirow{3}{*}{ Home region } & Zagreb & $54(64 \%)$ \\
\hline & Slavonia & $25(29 \%)$ \\
\hline & Dalmatia & $6(7 \%)$ \\
\hline \multirow{3}{*}{$\begin{array}{l}\text { Reported } \\
\text { symptoms }^{b}\end{array}$} & Eye & $56(66 \%)$ \\
\hline & Nasal & 75 (88\%) \\
\hline & Lung & 41 (48\%) \\
\hline
\end{tabular}

a17 children completed the diary in more than one pollen season ${ }^{b} 64$ children reported more than one symptom type 


\begin{tabular}{|c|c|c|c|}
\hline & & Odds Ratio $[\mathrm{Cl}]$ & $\mathrm{p}$ \\
\hline \multirow{4}{*}{ Age } & $4-7$ & Ref & \\
\hline & 8 & $0.26[0.05,1.31]$ & 0.096 \\
\hline & 9 & $0.16[0.02,1.07]$ & 0.054 \\
\hline & $10-12$ & $0.07[0.01,0.67]$ & 0.019 \\
\hline \multirow{2}{*}{ Gender } & Male & Ref & \\
\hline & Female & $0.68[0.02,21.56]$ & 0.825 \\
\hline \multirow{2}{*}{ Location } & At home & Ref & \\
\hline & Away from home & $0.54[0.30,0.97]$ & 0.036 \\
\hline \multicolumn{2}{|c|}{ Reported eye symptoms on previous day } & $45.21[32.56,62.78]$ & $<0.001$ \\
\hline \multicolumn{2}{|c|}{$\begin{array}{l}\text { Self (or parental)-reported allergic rhinitis symptoms } \\
\text { in child }\end{array}$} & $1.80[0.03,103.28]$ & 0.771 \\
\hline \multicolumn{2}{|c|}{ Self (or parental)-reported asthma symptoms in child } & $0.62[0.01,28.24]$ & 0.803 \\
\hline \multicolumn{2}{|c|}{ Taking nasal spray or nose drops on day of symptoms } & $18.91[9.48,37.69]$ & $<0.001$ \\
\hline \multicolumn{2}{|c|}{ Taking nasal spray or nose drops on previous day } & $0.31[0.16,0.61]$ & 0.001 \\
\hline \multicolumn{2}{|c|}{ Taking anti-allergy tablets on day of symptoms } & $0.89[0.04,22.21]$ & 0.940 \\
\hline \multicolumn{2}{|c|}{ Time spent being active outside } & $0.85[0.75,0.96]$ & 0.009 \\
\hline Monthly & $<€ 660$ & Ref & \\
\hline Household & $€ 660-€ 1320$ & $0.30[0.01,12.00]$ & 0.517 \\
\hline \multirow[t]{2}{*}{ Income } & $>€ 1320$ & $0.29[0.01,15.18]$ & 0.535 \\
\hline & 2012 & Ref & \\
\hline \multirow[t]{2}{*}{ Year } & 2013 & $4.48[2.21,9.07]$ & $<0.001$ \\
\hline & 2014 & $0.90[0.31,2.63]$ & 0.842 \\
\hline \multicolumn{2}{|c|}{ Mean daily temperature $\left({ }^{\circ} \mathrm{C}\right)$} & $1.09[1.03,1.16]$ & 0.002 \\
\hline \multicolumn{2}{|c|}{ Daily rainfall (mm) } & $0.99[0.97,1.02]$ & 0.586 \\
\hline \multicolumn{2}{|c|}{ Mean $\mathrm{SO}_{2}\left(\mu \mathrm{g} / \mathrm{m}^{3}\right)$ over previous 4 days } & $0.99[0.94,1.03]$ & 0.550 \\
\hline \multicolumn{2}{|c|}{ Mean PM10 $\left(\mu \mathrm{g} / \mathrm{m}^{3}\right)$ over previous 4 days } & $1.00[0.98,1.03]$ & 0.993 \\
\hline \multicolumn{2}{|c|}{ Mean $\mathrm{O}_{3}\left(\mu \mathrm{g} / \mathrm{m}^{3}\right)$ over previous 4 days } & $1.01[1.00,1.03]$ & 0.098 \\
\hline
\end{tabular}

Italics indicate significant findings

Deviance explained 66.7\% ; AIC $=1349.82 ;$ Dispersion parameter $=0.611$ 
Table 3: Model showing associations with the reported presence or absence of nasal symptoms

\begin{tabular}{|c|c|c|c|}
\hline & & Odds Ratio $[95 \% \mathrm{Cl}]$ & $\mathrm{p}$ \\
\hline \multirow{4}{*}{ Age } & $4-7$ & Ref & \\
\hline & 8 & $0.60[0.16,2.24]$ & 0.440 \\
\hline & 9 & $0.91[0.19,4.28]$ & 0.899 \\
\hline & $10-12$ & $0.79[0.13,4.64]$ & 0.787 \\
\hline \multirow{2}{*}{ Gender } & Male & Ref & \\
\hline & Female & $0.61[0.09,4.01]$ & 0.602 \\
\hline \multirow{2}{*}{ Location } & At home & Ref & \\
\hline & Away from home & $0.39[0.22,0.69]$ & 0.001 \\
\hline \multicolumn{2}{|c|}{ Reported nasal symptoms on previous day } & $71.45[50.41,101.26]$ & $<0.001$ \\
\hline \multicolumn{2}{|c|}{$\begin{array}{l}\text { Self (or parental)-reported allergic rhinitis symptoms } \\
\text { in child }\end{array}$} & $1.79[0.21,14.98]$ & 0.586 \\
\hline \multicolumn{2}{|c|}{ Self (or parental)-reported asthma symptoms in child } & $0.73[0.09,6.06]$ & 0.767 \\
\hline \multicolumn{2}{|c|}{ Taking nasal spray or nose drops on day of symptoms } & $10.07[5.18,19.55]$ & $<0.001$ \\
\hline \multirow{3}{*}{$\begin{array}{l}\text { Monthly } \\
\text { Household Income }\end{array}$} & $<€ 660$ & Ref & \\
\hline & $€ 660-€ 1320$ & $1.08[0.13,8.81]$ & 0.942 \\
\hline & $>€ 1320$ & $1.25[0.13,12.07]$ & 0.843 \\
\hline \multicolumn{2}{|c|}{ Child has been treated by doctor for worms } & $1.16[0.03,42.48]$ & 0.934 \\
\hline & 2012 & Ref & \\
\hline \multirow[t]{2}{*}{ Year } & 2013 & $2.87[1.37,6.02]$ & 0.004 \\
\hline & 2014 & $0.69[0.26,1.79]$ & 0.432 \\
\hline \multicolumn{2}{|c|}{ Mean daily temperature $\left({ }^{\circ} \mathrm{C}\right)$} & $1.07[1.01,1.14]$ & 0.012 \\
\hline \multicolumn{2}{|l|}{ Daily rainfall $(\mathrm{mm})$} & $0.98[0.96,1.00]$ & 0.037 \\
\hline \multicolumn{2}{|c|}{ Mean $\mathrm{SO}_{2}\left(\mu \mathrm{g} / \mathrm{m}^{3}\right)$ over previous 12 days } & $0.99[0.92,1.08]$ & 0.870 \\
\hline \multicolumn{2}{|c|}{ Mean PM10 $\left(\mu \mathrm{g} / \mathrm{m}^{3}\right)$ over previous 12 days } & $0.99[0.96,1.03]$ & 0.775 \\
\hline \multicolumn{2}{|c|}{ Mean $\mathrm{O}_{3}\left(\mu \mathrm{g} / \mathrm{m}^{3}\right)$ over previous 12 days } & $0.99[0.98,1.01]$ & 0.541 \\
\hline
\end{tabular}

Italics indicate significant findings

Deviance explained 73.1\%; $\mathrm{AIC}=1230.319 ;$ Dispersion parameter $=1.020$ 
Table 4: Model showing associations with the reported presence or absence of lung symptoms

\begin{tabular}{|c|c|c|c|}
\hline & & Odds Ratio $[95 \% \mathrm{Cl}]$ & $\mathrm{p}$ \\
\hline \multirow{4}{*}{ Age } & $4-7$ & Ref & \\
\hline & 8 & $0.39[0.03,4.54]$ & 0.443 \\
\hline & 9 & $1.55[0.11,21.81]$ & 0.741 \\
\hline & $10-12$ & $4.06[0.20,83.29]$ & 0.354 \\
\hline \multirow{2}{*}{ Gender } & Male & Ref & \\
\hline & Female & $1.00[0.04,27.43]$ & 0.999 \\
\hline \multirow{2}{*}{ Location } & At home & Ref & \\
\hline & Away from home & $0.83[0.32,2.10]$ & 0.683 \\
\hline \multicolumn{2}{|c|}{ Reported lung symptoms on previous day } & $35.40[21.42,58.48]$ & $<0.001$ \\
\hline \multicolumn{2}{|c|}{ Self (or parental)-reported allergic rhinitis symptoms in child } & $0.84[0.01,61.43]$ & 0.936 \\
\hline \multicolumn{2}{|c|}{ Self (or parental)-reported asthma symptoms in child } & $12.91[0.28,595.87]$ & 0.182 \\
\hline \multicolumn{2}{|c|}{ Taking asthma medication on day of symptoms } & $3.57[1.86,6.88]$ & $<0.001$ \\
\hline \multicolumn{2}{|c|}{ Time spent being active } & $0.78[0.64,0.96]$ & 0.014 \\
\hline Monthly & $<€ 660$ & Ref & \\
\hline Household & $€ 660-€ 1320$ & $0.14[0.00,6.63]$ & 0.311 \\
\hline Income & $>€ 1320$ & $0.23[0.00,14.33]$ & 0.473 \\
\hline \multicolumn{2}{|c|}{ Child has an asthmatic parent } & $8.03[0.14,454.72]$ & 0.302 \\
\hline Type of area & Rural area & Ref & \\
\hline \multirow[t]{2}{*}{ child lives in } & Urban area & $24.67[0.41,1468.70]$ & 0.117 \\
\hline & 2012 & Ref & \\
\hline \multirow[t]{2}{*}{ Year } & 2013 & $0.45[0.15,1.32]$ & 0.138 \\
\hline & 2014 & $0.16[0.03,0.88]$ & 0.032 \\
\hline \multicolumn{2}{|c|}{ Mean daily temperature $\left({ }^{\circ} \mathrm{C}\right)$} & $1.01[0.94,1.08]$ & 0.837 \\
\hline \multicolumn{2}{|c|}{ Daily rainfall (mm) } & $0.97[0.94,1.01]$ & 0.101 \\
\hline \multicolumn{2}{|c|}{ Mean $\mathrm{SO}_{2}\left(\mu \mathrm{g} / \mathrm{m}^{3}\right)$ over previous 19 days } & $0.99[0.85,1.15]$ & 0.911 \\
\hline \multicolumn{2}{|c|}{ Mean PM10 $\left(\mu \mathrm{g} / \mathrm{m}^{3}\right)$ over previous 19 days } & $1.01[0.94,1.09]$ & 0.737 \\
\hline \multicolumn{2}{|c|}{ Mean $\mathrm{O}_{3}\left(\mu \mathrm{g} / \mathrm{m}^{3}\right)$ over previous 19 days } & $1.00[0.98,1.03]$ & 0.762 \\
\hline
\end{tabular}

Italics indicate significant findings

Deviance explained 77\% ; AIC $=636.663 ;$ Dispersion parameter $=0.4246$ 
Figures

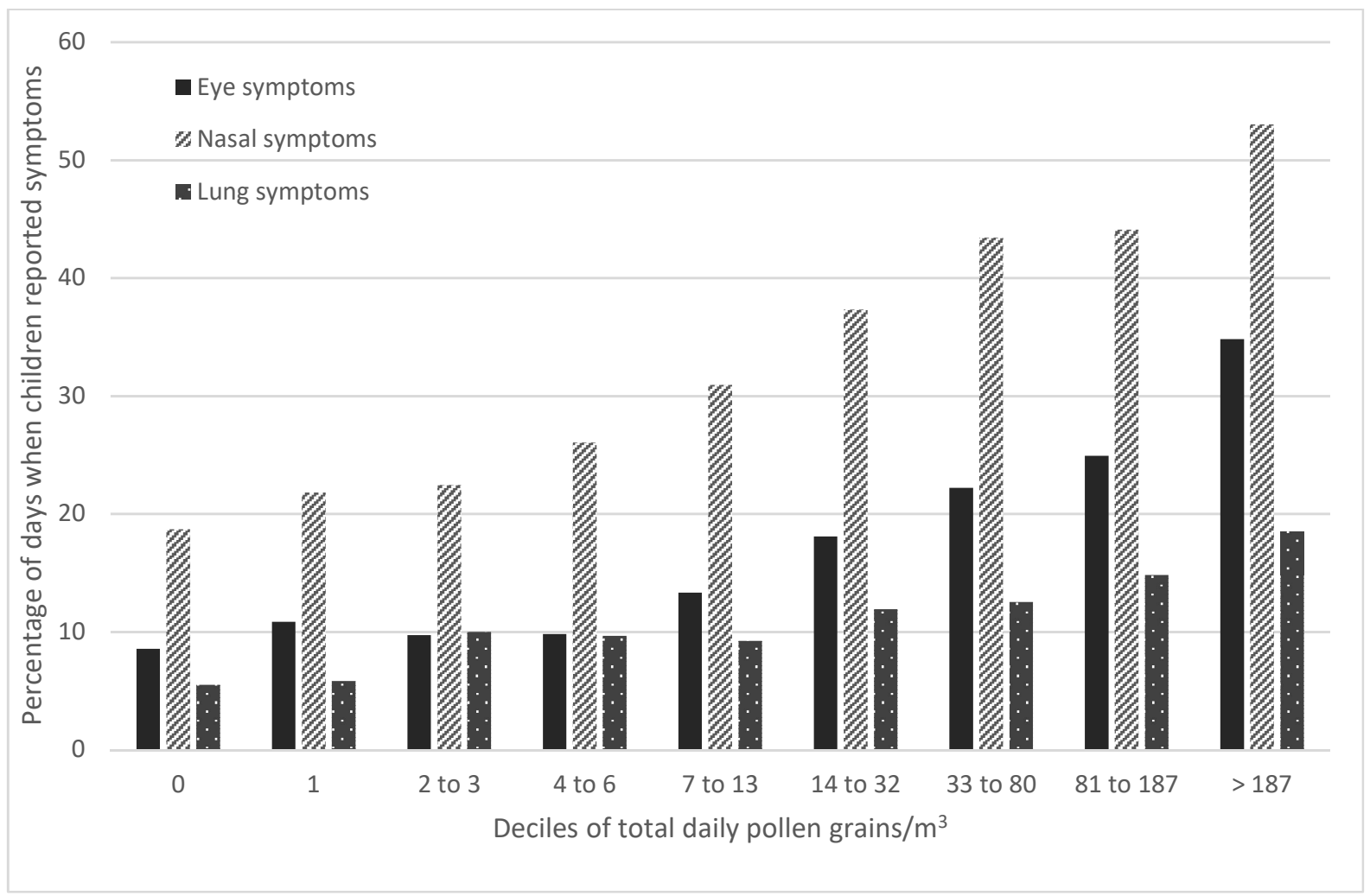

Figure 1: Relationship between total daily pollen grains $/ \mathrm{m}^{3}$ and percentage of days when children reported symptoms. 


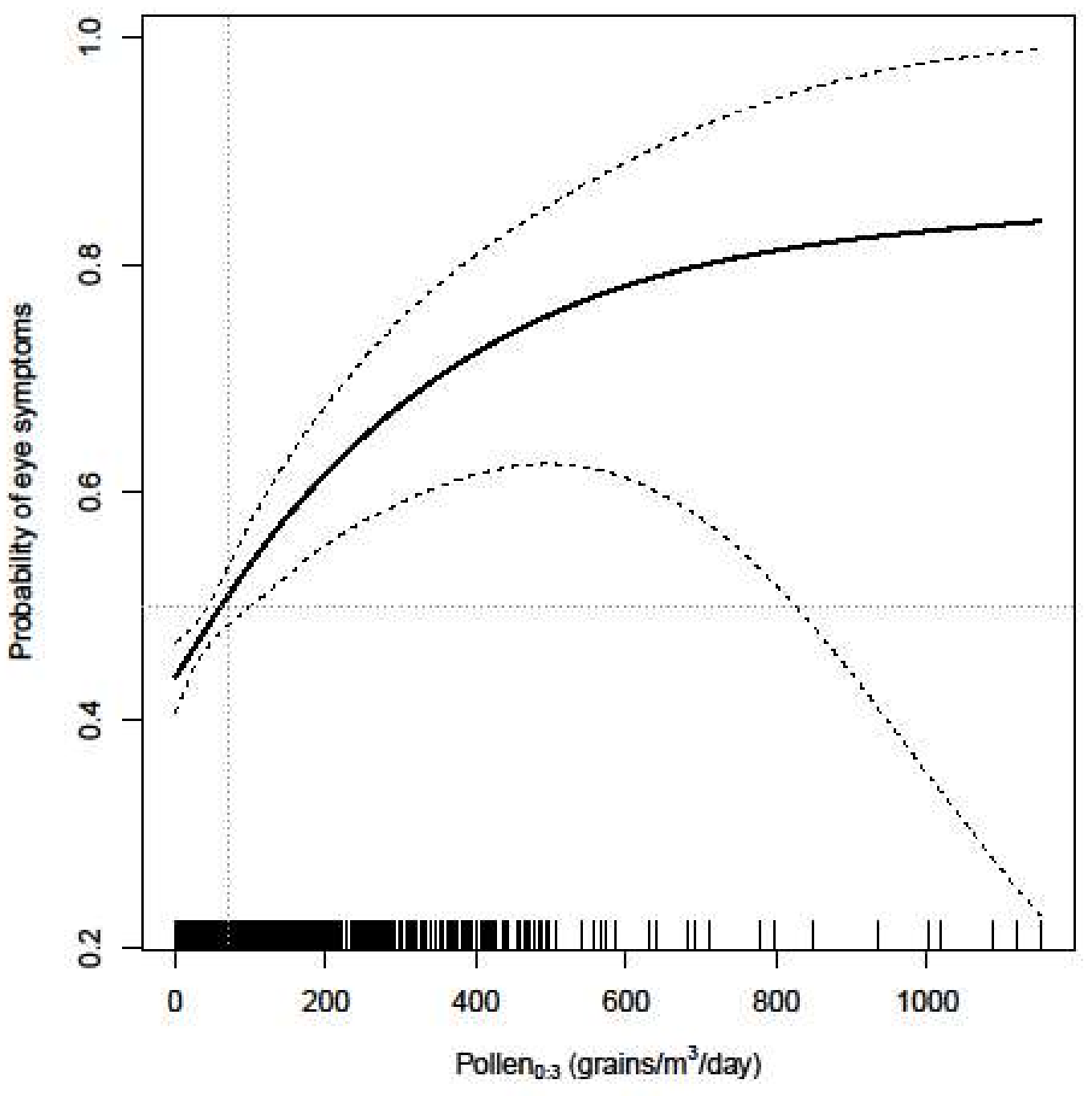

Figure 2: Relationship between mean daily pollen concentration lagged 0 to 3 days (Pollen03) and reported eye symptoms from a Generalised Additive Mixed Model. The $\mathrm{X}$ axis represents increasing pollen concentration. The rug (lines) at the bottom indicates the density of observations at each level of pollen. The $Y$ axis represents the probability of reported eye symptoms. The smooth line indicates the maximum likelihood estimates for the probability of symptoms, and the dashed lines represent the $95 \%$ confidence intervals. The dotted lines indicate the threshold at which $50 \%$ of children reported symptoms. 


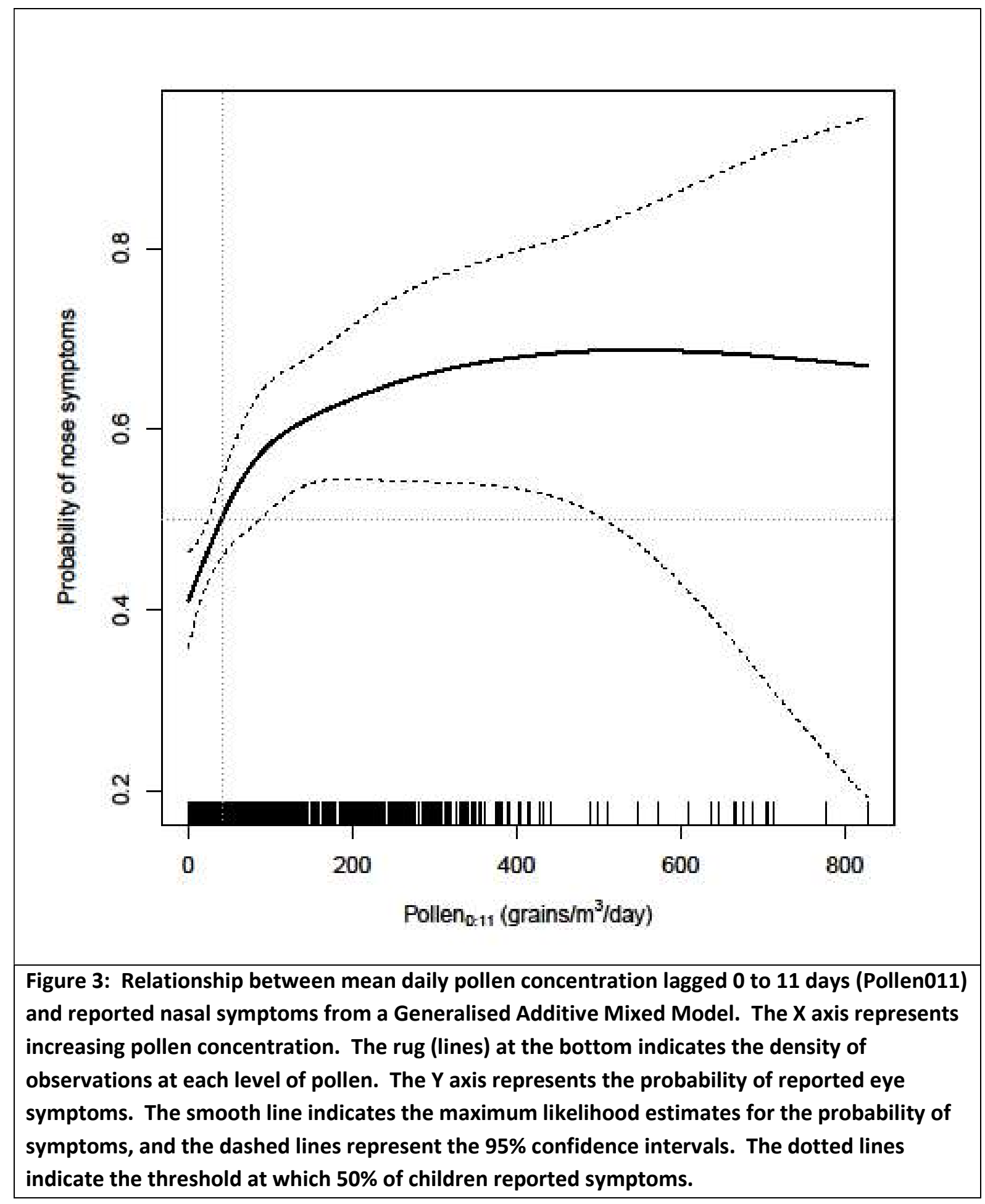




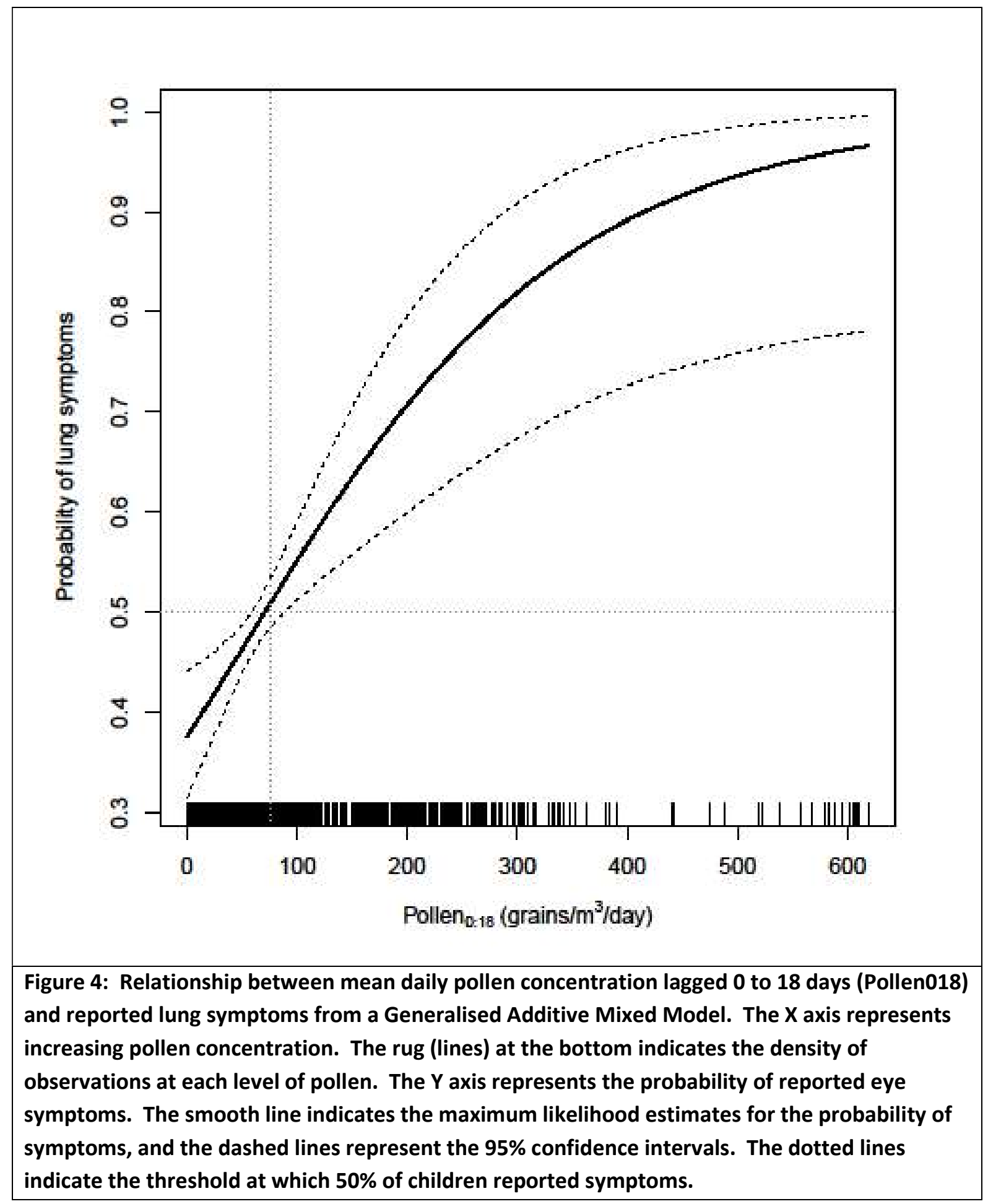




\section{References}

Agnew, M., Banic, I., Lake, I., Goodess, C., Grossi, C., Jones, N., Plavec, D., Epstein, M. \& Turkalj, M. 2018. Modifiable Risk Factors for Common Ragweed (Ambrosia artemisiifolia) Allergy and Disease in Children: A Case-Control Study. International Journal of Environmental Research and Public Health, 15, 1339.

Albertini, R., Ugolotti, M., Peveri, S., Valenti, M. T., Usberti, I., Ridolo, E. \& Dall'aglio, P. 2012. Evolution of ragweed pollen concentrations, sensitization and related allergic clinical symptoms in Parma (northern Italy). Aerobiologia, 28, 347-354.

Andrija Stampar Teaching Institute of Public Health. 2019. Pure prognosis for Croatia [Online]. Available: http://www.stampar.hr/hr/peludna-prognoza-za-hrvatsku [Accessed 14th January 2019].

Arnedo-Pena, A., García-Marcos, L., Bercedo-Sanz, A., Aguinaga-Ontoso, I., González-Díaz, C., GarcíaMerino, Á., Busquets-Monge, R., Suárez-Varela, M. M., Batlles-Garrido, J., Blanco-Quirós, A. A., López-Silvarrey, A., García-Hernández, G. \& Fuertes, J. 2013. Prevalence of asthma symptoms in schoolchildren, and climate in west European countries: an ecologic study. International Journal of Biometeorology, 57, 775-784.

Asher, M., Keil, U., Anderson, H., Beasley, R., Crane, J., Martinez, F., Mitchell, E., Pearce, N., Sibbald, B., Stewart, A. \& Et, A. 1995. International Study of Asthma and Allergies in Childhood (ISAAC): rationale and methods. European Respiratory Journal, 8, 483-491.

Bass, D. J., Delpech, V., Beard, J., Bass, P. \& Walls, R. S. 2000. Ragweed in Australia. Aerobiologia, 16, 107-111.

Bielory, L. 2010. Allergic conjunctivitis and the impact of allergic rhinitis. Curr Allergy Asthma Rep, 10, 122-34.

Bousquet, J., Arnavielhe, S., Bedbrook, A., Bewick, M., Laune, D., Mathieu-Dupas, E., Murray, R., Onorato, G. L., Pepin, J. L., Picard, R., Portejoie, F., Costa, E., Fonseca, J., Lourenco, O., Morais-Almeida, M., Todo-Bom, A., Cruz, A. A., Da Silva, J., Serpa, F. S., Illario, M., Menditto, E., Cecchi, L., Monti, R., Napoli, L., Ventura, M. T., De Feo, G., Larenas-Linnemann, D., Fuentes Perez, M., Huerta Villabolos, Y. R., Rivero-Yeverino, D., Rodriguez-Zagal, E., Amat, F., Annesi-Maesano, I., Bosse, I., Demoly, P., Devillier, P., Fontaine, J. F., Just, J., Kuna, T. P., Samolinski, B., Valiulis, A., Emuzyte, R., Kvedariene, V., Ryan, D., Sheikh, A., SchmidtGrendelmeier, P., Klimek, L., Pfaar, O., Bergmann, K. C., Mosges, R., Zuberbier, T., RollerWirnsberger, R. E., Tomazic, P., Fokkens, W. J., Chavannes, N. H., Reitsma, S., Anto, J. M., Cardona, V., Dedeu, T., Mullol, J., Haahtela, T., Salimaki, J., Toppila-Salmi, S., Valovirta, E., Gemicioglu, B., Yorgancioglu, A., Papadopoulos, N., Prokopakis, E. P., Bosnic-Anticevich, S., O'hehir, R., Ivancevich, J. C., Neffen, H., Zernotti, E., Kull, I., Melen, E., Wickman, M., Bachert, C., Hellings, P., Palkonen, S., Bindslev-Jensen, C., Eller, E., Waserman, S., Sova, M., De Vries, G., Van Eerd, M., Agache, I., Casale, T., Dykewickz, M., Naclerio, R. N., Okamoto, Y. \& Wallace, D. V. 2018. MASK 2017: ARIA digitally-enabled, integrated, person-centred care for rhinitis and asthma multimorbidity using real-world-evidence. Clin Transl Allergy, 8, 45.

Bousquet, P. J., Chinn, S., Janson, C., Kogevinas, M., Burney, P. \& Jarvis, D. 2007. Geographical variation in the prevalence of positive skin tests to environmental aeroallergens in the European Community Respiratory Health Survey I. Allergy, 62, 301-309. 
Breton, M. C., Garneau, M., Fortier, I., Guay, F. \& Louis, J. 2006. Relationship between climate, pollen concentrations of Ambrosia and medical consultations for allergic rhinitis in Montreal, 19942002. Sci Total Environ, 370, 39-50.

Burbach, G. J., Heinzerling, L. M., Röhnelt, C., Bergmann, K.-C., Behrendt, H. \& Zuberbier, T. 2009. Ragweed sensitization in Europe - GA2LEN study suggests increasing prevalence. Allergy, 64, 664-665.

Caillaud, D., Thibaudon, M., Martin, S., Ségala, C., Besancenot, J. P., Clot, B. \& François, H. 2014. Short-term effects of airborne ragweed pollen on clinical symptoms of hay fever in a panel of 30 patients. Journal of Investigational Allergology and Clinical Immunology, 24, 249-256.

Cakmak, S., Dales, R. E., Burnett, R. T., Judek, S., Coates, F. \& Brook, J. R. 2002. Effect of airborne allergens on emergency visits by children for conjunctivitis and rhinitis. Lancet, 359, 947-8.

Casas, L., Espinosa, A., Pekkanen, J., Asikainen, A., Borràs-Santos, A., Jacobs, J., Krop, E. J. M., Täubel, M., Hyvärinen, A., Heederik, D. \& Zock, J. P. 2017. School attendance and daily respiratory symptoms in children: influence of moisture damage. Indoor Air, 27, 303-310.

Comtois, P. \& Gagnon, L. 1988. Concentration pollinique et fréquence des symptômes de pollinose : une méthode pour déterminer les seuils cliniques. Revue Française d'Allergologie et d'Immunologie Clinique, 28, 279-286.

Erbas, B., Jazayeri, M., Lambert, K. A., Katelaris, C. H., Prendergast, L. A., Tham, R., Parrodi, M. J., Davies, J., Newbigin, E., Abramson, M. J. \& Dharmage, S. C. 2018. Outdoor pollen is a trigger of child and adolescent asthma emergency department presentations: A systematic review and meta-analysis. Allergy, 73, 1632-1641.

European Environment Agency 2015. Corine Land Cover Data.

Frey, U. \& Suki, B. 2008. Complexity of chronic asthma and chronic obstructive pulmonary disease: implications for risk assessment, and disease progression and control. Lancet (London, England), 372, 1088-1099.

Fumanal, B., Chauvel, B. \& Bretagnolle, F. 2007. Estimation of pollen and seed production of common ragweed in France. Annals of Agricultural and Environmental Medicine, 14, 233236.

Galzina, N., Baric, K., Šcepanovic, M., Goršic, M. \& Ostojic, Z. 2010. Distribution of invasive weed Ambrosia artemisiifolia L. in Croatia. Agriculturae Conspectus Scientificus, 75, 75-81.

Globe, G., Martin, M., Schatz, M., Wiklund, I., Lin, J., Von Maltzahn, R. \& Mattera, M. S. 2015. Symptoms and markers of symptom severity in asthma-content validity of the asthma symptom diary. Health and Quality of Life Outcomes, 13.

Hastie, T. \& Tibshirani, R. 1986. Generalized Additive Models. Statistical Science, 1, 297-310.

Illi, S., Von Mutius, E., Lau, S., Niggemann, B., Grüber, C. \& Wahn, U. 2006. Perennial allergen sensitisation early in life and chronic asthma in children: a birth cohort study. The Lancet, 368, 763-770.

Imai, C., Armstrong, B., Chalabi, Z., Mangtani, P. \& Hashizume, M. 2015. Time series regression model for infectious disease and weather. Environmental Research, 142, 319-327.

Jantunen, J., Saarinen, K. \& Rantio-Lehtimäki, A. 2012. Allergy symptoms in relation to alder and birch pollen concentrations in Finland. Aerobiologia, 28, 169-176.

Kay, G. G. 2000. The effects of antihistamines on cognition and performance. Journal of Allergy and Clinical Immunology, 105, S622-S627.

Kosti, R. I., Priftis, K. N., Anthracopoulos, M. B., Papadimitriou, A., Grigoropoulou, D., Lentzas, Y., Yfanti, K. \& Panagiotakos, D. B. 2012. The association between leisure-time physical 
activities and asthma symptoms among 10- to 12-year-old children: the effect of living environment in the PANACEA study. J Asthma, 49, 342-8.

Lake, I. R., Jones, N. R., Agnew, M., Goodess, C. M., Giorgi, F., Hamaoui-Laguel, L., Semenov, M. A., Solomon, F., Storkey, J., Vautard, R. \& Epstein, M. M. 2017. Climate change and future pollen allergy in Europe. Environmental Health Perspectives, 125, 385-391.

Leynaert, B., Neukirch, F., Demoly, P. \& Bousquet, J. 2000. Epidemiologic evidence for asthma and rhinitis comorbidity. J Allergy Clin Immunol, 106, S201-5.

Lucas, S. R. \& Platts-Mills, T. a. E. 2005. Physical activity and exercise in asthma: Relevance to etiology and treatment. Journal of Allergy and Clinical Immunology, 115, 928-934.

Matyasovszky, I., Makra, L., Tusnády, G., Csépe, Z., Nyúl, L. G., Chapman, D. S., Sümeghy, Z., Szűcs, G., Páldy, A., Magyar, D., Mányoki, G., Erostyák, J., Bodnár, K., Bergmann, K.-C., Deák, Á. J., Thibaudon, M., Albertini, R., Bonini, M., Šikoparija, B., Radišić, P., Gehrig, R., Rybníček, O., Severova, E., Rodinkova, V., Prikhodko, A., Maleeva, A., Stjepanović, B., lanovici, N., Berger, U., Seliger, A. K., Weryszko-Chmielewska, E., Šaulienè, I., Shalaboda, V., Yankova, R., Peternel, R., Ščevková, J. \& Bullock, J. M. 2018. Biogeographical drivers of ragweed pollen concentrations in Europe. Theoretical and Applied Climatology, 133, 277-295.

Mazerolle, M. J. 2006. Improving data analysis in herpetology: Using Akaike's information criterion (AIC) to assess the strength of biological hypotheses. Amphibia-Reptilia, 27, 169-180.

Medek, D. E., Kljakovic, M., Fox, I., Pretty, D. G. \& Prebble, M. 2012. Hay Fever in a Changing Climate: Linking an Internet-Based Diary with Environmental Data. EcoHealth, 9, 440-447.

Meltzer, E. O., Blaiss, M. S., Derebery, M. J., Mahr, T. A., Gordon, B. R., Sheth, K. K., Simmons, A. L., Wingertzahn, M. A. \& Boyle, J. M. 2009. Burden of allergic rhinitis: Results from the Pediatric Allergies in America survey. Journal of Allergy and Clinical Immunology, 124, S43-S70.

Naclerio, R. 2008. Intranasal corticosteroids reduce ocular symptoms associated with allergic rhinitis. Otolaryngology - Head and Neck Surgery, 138, 129-139.

Naclerio, R. M., Meier, H. L., Kagey-Sobotka, A., Adkinson, N. F., Jr., Meyers, D. A., Norman, P. S. \& Lichtenstein, L. M. 1983. Mediator release after nasal airway challenge with allergen. Am Rev Respir Dis, 128, 597-602.

Nathan, R. A. 2007. The burden of allergic rhinitis. Allergy and Asthma Proceedings, 28, 3-9.

Newhouse, C. P. \& Levetin, E. 2004. Correlation of environmental factors with asthma and rhinitis symptoms in Tulsa, OK. Ann Allergy Asthma Immunol, 92, 356-66.

Peternel, R., Culig, J., Srnec, L., Mitić, B., Vukusić, I. \& Hrga, I. 2005. Variation in ragweed (Ambrosia artemisiifolia L.) pollen concentration in central Croatia, 2002-2003. Annals of Agricultural and Environmental Medicine, 12, 11-16.

Peternel, R., Music Milanovic, S. \& Srnec, L. 2008. Airborne ragweed (Ambrosia artemisiifolia L.) pollen content in the city of Zagreb and implications on pollen allergy. Ann Agric Environ Med, 15, 125-30.

R Core Team 2018. R: A language and environment for statistical computing. Vienna, Austria.: R Foundation for Statistical Computing.

Rhodes, H. L., Thomas, P., Sporik, R., Holgate, S. T. \& Cogswell, J. J. 2002. A Birth Cohort Study of Subjects at Risk of Atopy. American Journal of Respiratory and Critical Care Medicine, 165, 176-180.

Ruëff, F., Przybilla, B., Walker, A., Gmeiner, J., Kramer, M., Sabanés-Bové, D., Küchenhoff, H. \& Herzinger, T. 2012. Sensitization to common ragweed in southern bavaria: Clinical and 
geographical risk factors in atopic patients. International Archives of Allergy and Immunology, 159, 65-74.

Rybníček, O. \& Jäger, S. 2001. Ambrosia (ragweed) in Europe. Allergy and Clinical Immunology International, 13, 60-66.

Salo, P. M., Arbes, S. J., Jaramillo, R., Calatroni, A., Weir, C. H., Sever, M. L., Hoppin, J. A., Rose, K. M., Liu, A. H., Gergen, P. J., Mitchell, H. E. \& Zeldin, D. C. 2014. Prevalence of allergic sensitization in the United States: Results from the National Health and Nutrition Examination Survey (NHANES) 2005-2006. Journal of Allergy and Clinical Immunology, 134, 350-359.

Scadding, G. K. 2015. Optimal management of allergic rhinitis. Archives of Disease in Childhood, 100, 576-582.

Sennhauser, F. H., Braun-Fahrländer, C. \& Wildhaber, J. H. 2005. The burden of asthma in children: a European perspective. Paediatric Respiratory Reviews, 6, 2-7.

Siroux, V., Boudier, A., Nadif, R., Lupinek, C., Valenta, R. \& Bousquet, J. 2018. Association between asthma, rhinitis and conjunctivitis multimorbidities with molecular IgE sensitization in adults. Allergy.

Smith, M., Cecchi, L., Skjøth, C. A., Karrer, G. \& Šikoparija, B. 2013. Common ragweed: A threat to environmental health in Europe. Environment International, 61, 115-126.

Solomon, W. R. 1984. Aerobiology of pollinosis. J Allergy Clin Immunol, 74, 449-61.

Storkey, J., Stratonovitch, P., Chapman, D. S., Vidotto, F. \& Semenov, M. A. 2014. A Process-Based Approach to Predicting the Effect of Climate Change on the Distribution of an Invasive Allergenic Plant in Europe. PLOS ONE, 9, e88156.

Symonds, M. R. E. \& Moussalli, A. 2011. A brief guide to model selection, multimodel inference and model averaging in behavioural ecology using Akaike's information criterion. Behavioral Ecology and Sociobiology, 65, 13-21.

Thibaudon, M., Šikoparija, B., Oliver, G., Smith, M. \& Skjøth, C. A. 2014. Ragweed pollen source inventory for France - The second largest centre of Ambrosia in Europe. Atmospheric Environment, 83, 62-71.

Tobias, A., Galan, I. \& Banegas, J. R. 2004. Non-linear short-term effects of airborne pollen levels with allergenic capacity on asthma emergency room admissions in Madrid, Spain. Clin Exp Allergy, 34, 871-8.

Villeneuve, P. J., Doiron, M. S., Stieb, D., Dales, R., Burnett, R. T. \& Dugandzic, R. 2006. Is outdoor air pollution associated with physician visits for allergic rhinitis among the elderly in Toronto, Canada? Allergy, 61, 750-8.

Voukantsis, D., Berger, U., Tzima, F., Karatzas, K., Jaeger, S. \& Bergmann, K. C. 2015. Personalized symptoms forecasting for pollen-induced allergic rhinitis sufferers. International Journal of Biometeorology, 59, 889-897.

Voukantsis, D., Niska, H., Karatzas, K., Riga, M., Damialis, A. \& Vokou, D. 2010. Forecasting daily pollen concentrations using data-driven modeling methods in Thessaloniki, Greece. Atmospheric Environment, 44, 5101-5111.

Wood, S. N. 2006. Generalized Additive Models: an introduction with R. , Florida, Chapman \& Hall/CRC.

Zheng, X.-Y., Ding, H., Jiang, L.-N., Chen, S.-W., Zheng, J.-P., Qiu, M., Zhou, Y.-X., Chen, Q. \& Guan, W.-J. 2015. Association between Air Pollutants and Asthma Emergency Room Visits and 
Hospital Admissions in Time Series Studies: A Systematic Review and Meta-Analysis. PloS one, 10, e0138146-e0138146.

Zuberbier, T., Lötvall, J., Simoens, S., Subramanian, S. V. \& Church, M. K. 2014. Economic burden of inadequate management of allergic diseases in the European Union: a GA2LEN review.

Allergy, 69, 1275-1279.

Table S1: Significance of daily pollen lags for eye, nose and lung symptoms

\begin{tabular}{l|ccc} 
& \multicolumn{3}{|c}{$\mathrm{p}$} \\
Day & Eye symptoms & Nose symptoms & Lung symptoms \\
\hline 0 & $<0.001$ & $<0.001$ & $<0.001$ \\
1 & $<0.001$ & $<0.001$ & $<0.001$ \\
2 & $<0.001$ & 0.001 & $<0.001$ \\
3 & $<0.001$ & $<0.001$ & $<0.001$ \\
4 & 0.010 & $<0.001$ & 0.002 \\
5 & 0.016 & 0.003 & $<0.001$ \\
6 & 0.028 & $<0.001$ & $<0.001$ \\
7 & 0.024 & $<0.001$ & $<0.001$ \\
8 & 0.114 & 0.001 & $<0.001$ \\
9 & 0.035 & $<0.001$ & $<0.001$ \\
10 & 0.074 & 0.001 & $<0.001$ \\
11 & 0.009 & 0.001 & $<0.001$ \\
12 & 0.210 & 0.035 & $<0.001$ \\
13 & 0.847 & 0.081 & $<0.001$ \\
14 & 0.761 & 0.117 & 0.001 \\
15 & 0.807 & 0.006 & 0.001 \\
16 & 0.737 & 0.043 & $<0.001$ \\
17 & 0.555 & 0.028 & $<0.001$ \\
18 & 0.370 & 0.049 & 0.007 \\
19 & 0.076 & 0.498 & 0.019 \\
20 & 0.223 & 0.961 & 0.049 \\
& & &
\end{tabular}


Table S2: Explanatory variables used in analysis

\begin{tabular}{|c|c|}
\hline & Variable \\
\hline \multirow[t]{29}{*}{ Time series } & Mean Pollen concentration lagged over days zero to three (Pollen 0:3) \\
\hline & Mean Pollen concentration lagged over days zero to eleven (Pollen 0:11) \\
\hline & Mean Pollen concentration lagged over days zero to eighteen (Pollen 0:18) \\
\hline & Day of the week \\
\hline & Weekend \\
\hline & Year $(2012 ; 2013 ; 2014)$ \\
\hline & Season (Early or late pollen season) \\
\hline & Location of child in Day (At home or Away from home) \\
\hline & Reported eye symptoms on previous day \\
\hline & Reported nasal symptoms on previous day \\
\hline & Reported lung symptoms on previous day \\
\hline & Self (or parental)-reported allergic rhinitis symptoms in child \\
\hline & Self (or parental)-reported allergic asthma symptoms in child \\
\hline & Taking nasal spray or nose drops on day of symptoms \\
\hline & Taking nasal spray or nose drops on previous day \\
\hline & Taking anti-allergy tablets on day of symptoms \\
\hline & Taking anti-allergy tablets on previous day \\
\hline & Taking asthma medication on day of symptoms \\
\hline & Taking asthma medication on previous day \\
\hline & Time spent being active \\
\hline & Time spent being active outside \\
\hline & Mean daily temperature $\left({ }^{\circ} \mathrm{C}\right)$ \\
\hline & Maximum daily temperature $\left({ }^{\circ} \mathrm{C}\right)$ \\
\hline & Minimum daily temperature $\left({ }^{\circ} \mathrm{C}\right)$ \\
\hline & Daily rainfall $(\mathrm{mm})$ \\
\hline & Mean $\mathrm{SO}_{2}\left(\mu \mathrm{g} / \mathrm{m}^{3}\right)$ over previous $4 / 12 / 19$ days \\
\hline & Mean PM10 $\left(\mu \mathrm{g} / \mathrm{m}^{3}\right)$ over previous $4 / 12 / 19$ days \\
\hline & Mean $\mathrm{NO}_{2}\left(\mu \mathrm{g} / \mathrm{m}^{3}\right)$ over previous $4 / 12 / 19$ days \\
\hline & Mean $\mathrm{O}_{3}\left(\mu \mathrm{g} / \mathrm{m}^{3}\right)$ over previous $4 / 12 / 19$ days \\
\hline \multirow[t]{16}{*}{ Individual } & Age at entry into study \\
\hline & Gender \\
\hline & Sensitisation to other allergens \\
\hline & Atopic parent \\
\hline & Child order \\
\hline & Use of antibiotics in first year of life \\
\hline & Maternal smoking in pregnancy \\
\hline & Child has been treated by doctor for worms \\
\hline & Respiratory infection in childhood \\
\hline & Does child sleep on feather pillow \\
\hline & Asthmatic parent \\
\hline & Has atopic family member \\
\hline & Number of bedrooms in home \\
\hline & Number of adults in household \\
\hline & Education of father (Higher than secondary level; High school diploma or lower) \\
\hline & Education of Mother (Higher than secondary level; High school diploma or lower) \\
\hline
\end{tabular}




\begin{tabular}{|l|l|}
\hline & Monthly Household Income $(<€ 660 ; € 660-€ 1320 ;>€ 1320)$ \\
\hline & Lives in Urban or Rural area \\
\hline
\end{tabular}




\section{Eye model}

Core model

Monthly household Income

1955.25

Mean $\mathrm{O}_{3}\left(\mu \mathrm{g} / \mathrm{m}^{3}\right)$ over previous 4 days

1750.75

Location (at home or away from home)

1640.88

Taking anti-allergy tablets on day of symptoms

1564.37

Taking nasal spray or nose drops on day of symptoms

1502.76

Self (or parental)-reported allergic rhinitis symptoms in child

1446.85

Self (or parental)-reported asthma symptoms in child

1399.50

Mean PM10 $\left(\mu \mathrm{g} / \mathrm{m}^{3}\right)$ over previous 4 days

1373.26

Mean $\mathrm{SO}_{2}\left(\mu \mathrm{g} / \mathrm{m}^{3}\right)$ over previous 4 days

1363.46

Taking nasal spray or nose drops on previous day

1354.90

Time spent being active outside

1349.82

\section{Nose model}

Core model

2369.80

Monthly household Income

1815.58

Mean $\mathrm{O}_{3}\left(\mu \mathrm{g} / \mathrm{m}^{3}\right)$ over previous 12 days

1536.82

Location (at home or away from home)

1447.77

Taking nasal spray or nose drops on day of symptoms

1385.68

Child has been treated by doctor for worms

1330.46

Mean PM10 $\left(\mu \mathrm{g} / \mathrm{m}^{3}\right)$ over previous 12 days

Self (or parental)-reported allergic rhinitis symptoms in child

1261.51

Mean $\mathrm{SO}_{2}\left(\mu \mathrm{g} / \mathrm{m}^{3}\right)$ over previous 12 days

1241.56

Self (or parental)-reported asthma symptoms in child

\section{Lung model}

Core model

1381.89

Mean $\mathrm{O}_{3}\left(\mu \mathrm{g} / \mathrm{m}^{3}\right)$ over previous 19 days

1063.19

Monthly household Income

Mean PM10 $\left(\mu \mathrm{g} / \mathrm{m}^{3}\right)$ over previous 19 days

Location (at home or away from home)

Mean $\mathrm{SO}_{2}\left(\mu \mathrm{g} / \mathrm{m}^{3}\right)$ over previous 19 days

Child has asthmatic parent

673.04

Taking asthma medication on day of symptoms

Self (or parental)-reported allergic rhinitis symptoms in child 
Core model: Child (random effect), Area (random effect), average pollen (over 4/12/19 days), reported eye/nose/lung symptoms on previous day, gender, age, year, mean daily temperature $\left({ }^{\circ} \mathrm{C}\right)$, daily rainfall $(\mathrm{mm})$ 